\title{
A robust crude oil supply chain design under uncertain demand and market price: A case study
}

\author{
Heidar Beiranvand, Mahdi Ghazanfari, Hadi Sahebi*, and Mir Saman Pishvaee \\ School of Industrial Engineering, Iran University of Science and Technology, Tehran, Iran
}

Received: 3 February 2018 / Accepted: 28 August 2018

\begin{abstract}
In today's global economy, the oil industry plays a vital role and has an effect on most of countries within leading business environments, particularly in oil producing countries. To deal with the complexity of the crude oil supply network, a mathematical programming model is developed to formulate a crude oil supply chain. A robust optimization model is developed to maximize the profitability of the entire chain and take uncertainties of price and demand into account. The results show that according to the real case study data the robust optimization technique will increase the profitability of the crude oil supply chain.
\end{abstract}

\section{Introduction}

Crude oil as a main energy source nowadays has a vital role in today's business. The most energy experts predict that world primary energy demand will double by the year 2030, increasing from 9 to 18 Gtoe. There are a number of different energy scenarios that forecast this demand will roughly triple to 25 or 30 Gtoe by the year 2050. According to these outlooks, by 2050 fossil fuels will supply no more than two thirds of all energy consumed, as against $85 \%$ today [1].

The crude oil supply network management is extremely complicated and deals with oilfield development, crude oil transportation, oil refining, petrochemical production, and products distribution. Complex studies are conducted to decide on different problems at this supply network, optimize this competitive system, and gain competitive advantages. Crude Oil Supply Chain (COSC) falls into four broad parts: crude oilfields, petroleum refineries, petrochemicals, and distribution facilities. Until recent times, COSC network structures have been rarely considered comprehensively. Due to increasing competition, designing and planning of extensive crude oil supply chains (including all entities and segments of upstream, midstream, and downstream network) and the goal of achieving the maximum profitability of the entire chain, some researches had recently been undertaken [2]. The key issue to configure the optimal crude oil network design is the uncertainty in the price and demand. As a result, deterministic mathematical programming cannot be relied on, under such uncertain

\footnotetext{
* Corresponding author: hadi_sahebi@iust.ac.ir
}

conditions in the crude oil context, to reach maximum profitability. Sometimes defining specific stochastic scenarios is impossible through lack of detailed information. That's the reason behind using the robust mathematical programming to control risks in different situations and reduce their negative effects. On that account, this study is based on optimization with robust mathematical programming to find robust solutions under uncertain situations of this problem.

La Londe and Masters [3] proposed that a supply chain is a set of firms that pass materials forward. Normally, several independent firms are involved in manufacturing a product and placing it in the hands of the end user in a supply chain raw material and component producers, product assemblers, wholesalers, retailer merchants and transportation companies are all members of a supply chain. Mentzer et al. [4] defined the supply chain as a set of three or more entities (organizations or individuals) directly involved in the upstream and downstream flows of products, services, finances, and/or information from a source to a customer. There is no agreement on whether the COSC is divided into two or three sections. In this paper, the second classification scheme (i.e. upstream, midstream, and downstream) is selected. Considering the main entities of this supply network can be a suitable solution to studying the structure of the COSC. As shown in Figure 1, four key facilities (i.e. oilfield, refinery, petrochemical, and distribution center) are remarked to consider the structure of presented models in the literature. Neiro and Pinto [5] addressed a deterministic mathematical programming model to make tactical and operational decisions on several segments of the crude oil industry. Their COSC model comprised oilfield infrastructure, crude oil transportation modes, storage 

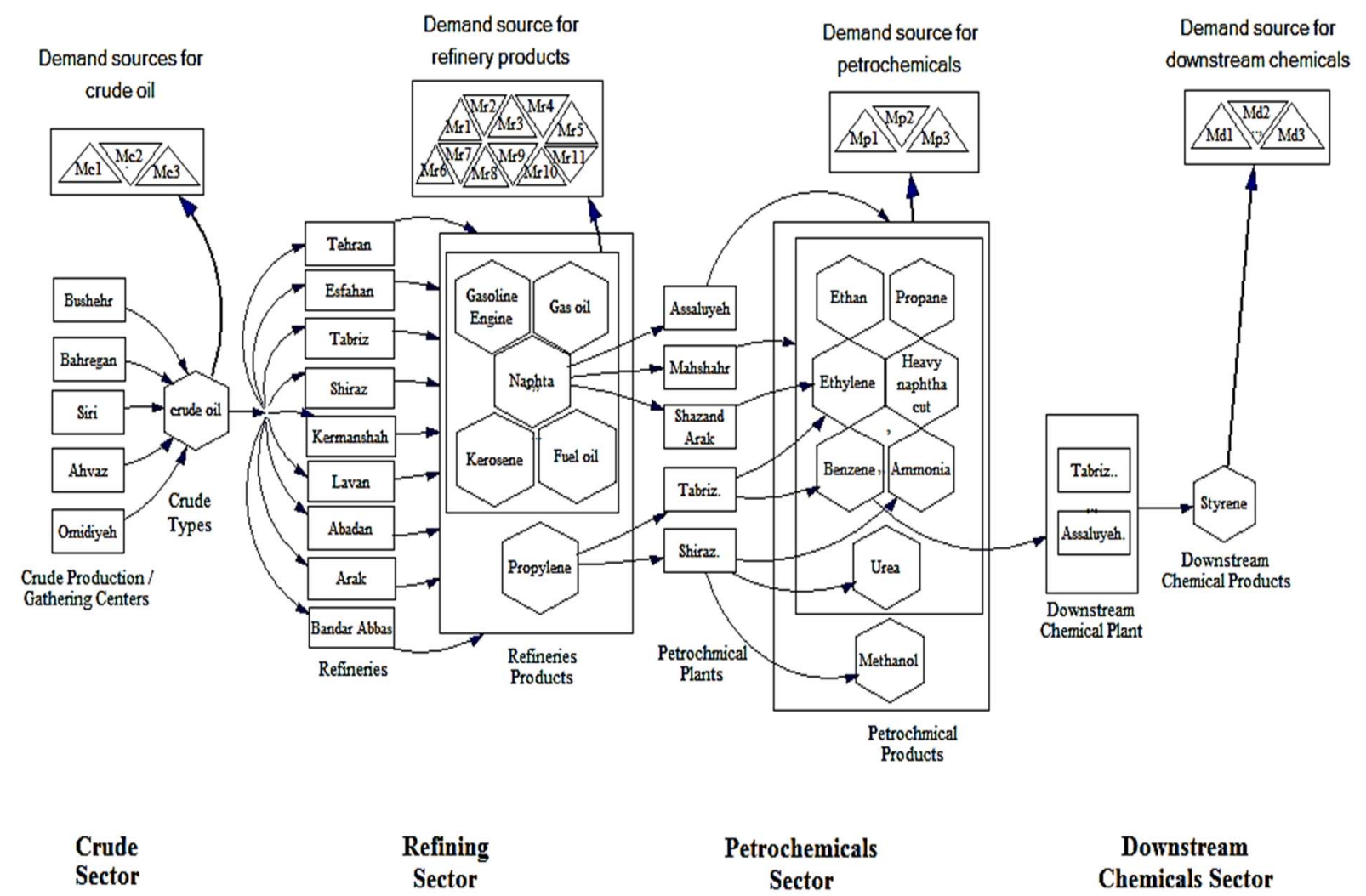

\section{Downstream \\ Chemicals Sector}

Fig. 1. Supply chain network for the crude oil industry (Case of I.R. Iran).

tanks, refinery operations, and products distribution. Particular frameworks were presented to reach decisions on stream flow rates, product properties, production planning, inventory management, and facilities allocations. MirHassani [6] also focused on the tactical variables to distribute crude oil products among a capacitated crude oil supply network. He formulated this COSC to study the long-term transportation of crude oil and its products by ship, pipeline, truck, and railway. This study provides new insight into this field by surmounting the demand uncertainty related issues. In this direction, Oliveira et al. [7] studied demand uncertainty more deeply and put forward a risk measure to formulate supply investment planning problem in the inventory capacity of crude oil products. They presented a new Lagrangian decomposition approach and a hybrid algorithm to deal with a large-scale two-stage model. Oliveira et al. [8] developed their model and recommended an accelerating benders stochastic decomposition to reduce the solution time of their largescale problem. One of the most comprehensive distribution networks, from structural point of view, was addressed by Fernandes et al. [9]. A deterministic downstream COSC network design and a planning model were developed to figure out optimal depot locations, depot capacities, transportation routes and modes, and refinery planning. They considered a multi-entity (refineries, transportation modes, and storage depots) and multi-transportation downstream crude oil supply network.
In addition to downstream problems, oilfield development and crude oil transportation are two significant upstream problems in the crude oil supply management context. Chen et al. [10] configured an import crude oil transportation network to save international logistics costs. They put their concentration on China's oil production and consumption nodes to investigate a detailed study of sink and source nodes, stream flow of crude oil, and transportation routes in China's crude oil supply network. Then, a mathematical programming model was developed by them and carried out using Genetic Algorithm. Gupta and Grossmann [11] studied upstream problems more. They presented a seminal generic strategic and tactical model for offshore oilfield development problems. This model scheduled FPSO (Floating Production, Storage, and Offloading) installation and expansion as well as involving well drilling schedule. Connection between the fields and the FPSOs and the production planning were also determined by the model. Sahebi and Nickel [12] attacked to an extensive upstream crude oil supply chain design problem. Their model considered oilfield developments decisions, determined optimal allocation of facilities, studied transportation modes, and figured out the best markets to which crude oil be exported . Elsholkami and Elkamel [13] focused on the efficiency and environmental sustainability of the sulfur supply chain for sour gas processing. They considered supply and demand uncertain and investigated their effects on the design of the supply chain. Casault et al. [14] studied 
North American oil and gas exploration and production firms. They showed that these firms have rapid and large fluctuation in stock value. As a result, dealing with uncertainty is essential in these firms, although in these kinds of studies, mostly, was ignored.

At the midstream, most of researchers put their attention on the production planning problems in refineries. A complete refinery process was formulated by Neiro and Pinto [5]. Processing units of a refinery, intermediate streams, storage tanks, and transportation modes were taken into account. Decision variables including properties, stream flow rates, production and inventory planning, and entities assignment were considered. Chufu et al. [15] formulated a hybrid model for optimal production planning in refineries. They developed a programming model to study uncertainty in demand. In this direction, a robust planning model of multisite refinery supply chain was addressed by Al-Qahtani and Elkamel [16]. This work considered the multisite integration and coordination problems within a crude oil supply network, especially midstream section, under uncertainty. The main decision variables were process input flow rates, blending levels, and transshipment levels. The risk of customer satisfaction and inventory violation were very important in the crude oil supply management [16]. For this purpose, a stochastic refinery planning model was extended by means of conditional value-at-risk theory. Tong et al. took, simultaneously, demand amount uncertainty and product yield fluctuation into account [17].

When the historical data is well enough to specify scenarios and their probabilities, the approach of stochastic optimization can be a suitable programming method. Sometimes this may not be possible to define scenarios specifically by available historical data because of indistinctive pattern amongst the data and high fluctuation of parameter that is why the stochastic programming cannot be an effective approach to dealing with uncertain crude oil's price. Since there are too many influential factors behind crude oil price changes, predicting the probabilities of scenarios are also impossible in the petroleum industry. Consequently, the robust optimization method was more appropriate to be employed by a decision-maker to have a suboptimal solution. The solution remains feasible and close-to-optimal under fluctuation of data. This method can even be used when there is limited information about the uncertain parameters. Then, the robust optimization was the proper method to deal with uncertainty in demand and price accurately. Leiras et al. [18] extended the work of Al-Qahtani and Elkamel [16] to account for raw material cost, final products prices, and demand uncertainty. A robust optimization method was applied by them.

A few papers in the literature studied more than one segment of the crude oil supply network. Oliveira and Hamacher [19] formulated midstream and downstream of the COSC simultaneously. They addressed a model to optimize the investment in the logistics infrastructure to distribute crude oil products. A production planning in refineries and flow material planning between refineries and distribution centers were considered under uncertainty. A similar model under demand and price uncertainty was presented by Ribas et al. [20] to formulate Brazil's petroleum supply chain. Al-Othman et al. [21] proposed an extensive petroleum supply network model. They addressed a complete spatial integration including upstream, midstream, and downstream. Uncertainties were introduced in prices and demands. A two-stage stochastic programming approach was developed to determine optimal solution.

In a nutshell, uncertainty in demand and price for energy sources, especially crude oil, is a leading factor which should be born in mind to make more realistic decisions [1]. To deal with these high uncertain parameters with difficulty in specifying scenarios, to our knowledge, the robust optimization was the most appropriate method in crude oil supply context. Moreover, spatial integration had a significant effect on the profitability of the whole supply network, which was ignored in the literature. It is a proper scientific way to have a real case study and analyze the results to validate the proposed model. One thing more, the crude oil supply chain has a striking similarity to the LNG supply chain [20-24]. A summary of the literature is shown in Table 1. According to this, the main contributions of current work are as follows: spatial integration to form a comprehensive structure of the COSC, taking uncertain demands and prices into account, determining the nearoptimal solution under the robust optimization method, validating the presented mathematical programming model by providing a real case study.

Owing to the complexity of the COSC, decision making was a difficult process in this context. From this background, a mathematical programming model was developed to formulate Iranian crude oil supply chain, which consisted of oilfield platforms, oil refineries, petrochemicals and markets. Market prices and demands are uncertain intended and expressed by a series of scenarios. A robust optimization model was developed to take uncertainties of price and demand into account and maximize the profitability of the entire chain. In this model, reducing the differences of the mean scenario with the other scenarios and the violations of constraints demand possibility was considered. The field of energy, especially petroleum, was faced with high sensitivity and could have a direct impact on a country's economy. Therefore, in addition to reducing the average costs of all scenarios, the model considered reducing the difference between average costs and reducing the costs of any of the scenarios accordingly. Demand constraints in the model needed to be violated to increase profitability; this makes the product shipped to demand client differ from the amount of actual demand. For this purpose, a cost constraint violation was considered to demand constraint the profitability of models by which in different scenarios had been examined. In this paper, different scenarios of the model have been studied. The optimization method is resolved based on the two-stage condition. The results illustrate that under uncertain demands and prices the robust optimization technique will increase the profitability of the crude oil supply chain.

The reminder of this paper is organized as follows: The deterministic optimization model of the supply chain is described in Section 3, followed by a description of the robust optimization mathematical modeling Section 4 . 
Table 1. A summary of the crude oil supply chain's literature.

\begin{tabular}{|c|c|c|c|c|c|c|c|c|c|c|c|c|c|}
\hline \multirow[t]{2}{*}{ References } & \multicolumn{4}{|c|}{ Structure: segments and entities } & \multicolumn{4}{|c|}{ Modeling approach } & \multicolumn{4}{|c|}{$\begin{array}{c}\text { Structure: } \\
\text { segments and } \\
\text { entities }\end{array}$} & \multirow[t]{2}{*}{$\begin{array}{c}\text { Case study } \\
\text { (crude oil } \\
\text { chain supply) }\end{array}$} \\
\hline & Oilfield & Refinery & Petrochemical & Distribution & $\begin{array}{c}\text { Deterministic } \\
\text { Prog. }\end{array}$ & $\begin{array}{l}\text { Stochastic } \\
\text { Prog. }\end{array}$ & $\begin{array}{l}\text { Robust } \\
\text { Opti. }\end{array}$ & $\begin{array}{l}\text { Fuzzy } \\
\text { Prog. }\end{array}$ & $\begin{array}{c}\text { Oil } \\
\text { Production }\end{array}$ & Price & Demand & Others & \\
\hline Neiro and Pinto [5] & $\mathrm{x}$ & $\mathrm{x}$ & & $\mathrm{x}$ & $\mathrm{x}$ & & & & & & & & \\
\hline $\begin{array}{l}\text { Al-Othman } \\
\text { et al. }[21]\end{array}$ & $\mathrm{x}$ & $\mathrm{x}$ & $\mathrm{x}$ & $\mathrm{x}$ & & $\mathrm{x}$ & & & & $\mathrm{x}$ & $\mathrm{x}$ & & \\
\hline Chufu et al. [15] & & $\mathrm{x}$ & & & & $\mathrm{x}$ & & & & & $\mathrm{x}$ & & \\
\hline MirHassani [6] & & $\mathrm{x}$ & & $\mathrm{x}$ & & $\mathrm{x}$ & & & & & $\mathrm{x}$ & & \\
\hline Ribas et al. [20] & $\mathrm{x}$ & $\mathrm{x}$ & & $\mathrm{x}$ & & $\mathrm{x}$ & $\mathrm{x}$ & & $\mathrm{x}$ & $\mathrm{x}$ & $\mathrm{x}$ & & Brazil \\
\hline $\begin{array}{l}\text { Al-Qahtani } \\
\text { and Elkamel [16] }\end{array}$ & & $\mathrm{x}$ & & & & $\mathrm{x}$ & $\mathrm{x}$ & & & $\mathrm{x}$ & $\mathrm{x}$ & & \\
\hline Chen et al. [10] & $\mathrm{x}$ & & & $\mathrm{x}$ & $\mathrm{x}$ & & & & & & & & China \\
\hline Leiras et al. [18] & & $\mathrm{x}$ & & & & & $\mathrm{x}$ & & & $\mathrm{x}$ & $\mathrm{x}$ & $\mathrm{x}$ & \\
\hline Tong et al. [17] & $\mathrm{x}$ & $\mathrm{x}$ & & $\mathrm{x}$ & & $\mathrm{x}$ & & & & & $\mathrm{x}$ & $\mathrm{x}$ & \\
\hline $\begin{array}{l}\text { Oliveira and } \\
\text { Hamacher [19] }\end{array}$ & & $\mathrm{x}$ & & $\mathrm{x}$ & & $\mathrm{x}$ & & & & & $\mathrm{x}$ & & $\begin{array}{l}\text { Northern } \\
\text { Brazil }\end{array}$ \\
\hline $\begin{array}{l}\text { Gupta and } \\
\text { Grossmann [11] }\end{array}$ & $\mathrm{x}$ & & & & $\mathrm{x}$ & & & & & & & & \\
\hline Fernandes et al. [9] & & $\mathrm{x}$ & & $\mathrm{x}$ & $\mathrm{x}$ & & & & & & & & Portugal \\
\hline Oliveira et al. [7] & $\mathrm{x}$ & & & $\mathrm{x}$ & & $\mathrm{x}$ & & & & & $\mathrm{x}$ & & \\
\hline Oliveira et al. [8] & $\mathrm{x}$ & $\mathrm{x}$ & & $\mathrm{x}$ & & $\mathrm{x}$ & & & & & $\mathrm{x}$ & & \\
\hline $\begin{array}{l}\text { Sahebi and } \\
\text { Nickel [12] }\end{array}$ & $\mathrm{x}$ & $\mathrm{x}$ & & & $\mathrm{x}$ & & & & & & & & \\
\hline Current study & $\mathrm{x}$ & $\mathrm{x}$ & $\mathrm{x}$ & $\mathrm{x}$ & & & $\mathrm{x}$ & & & $\mathrm{x}$ & $\mathrm{x}$ & & Iran \\
\hline
\end{tabular}


The proposed mathematical models were tested on a hypothetical supply chain network, which is described in Section 5. Deterministic and stochastic results are presented and discussed in Section 6, and the derived conclusions are stated in Section 7.

\section{Problem definition}

Iran's crude oil supply chain consists of four sections. Symbolic Iran's crude oil supply chain network is shown in Figure 1. This figure contains all activities related to production and processing of crude oil as well as depots and transportation to the demand sources.

In this chain, a great deal of petroleum is exported to world markets while some of it is transmitted to local refineries and is refined. Every refinery refines a certain amount of petroleum. Some of refined products are produced in the refining units and can be exported to demand centers or applied for local usage or used in petrochemical plants. Petrochemical products are exported or used in the downstream chemical industry. It is clear that demand centers (markets) of petroleum and refined products and downstream products are different and may be determined by economic conditions and specific geographical locations. Petroleum production planning is usually based on a monthly schedule. The demand of each sector in each period is fulfilled or transferred to the next period as the deficiency or counted as the lost demand. It is caused that the sales departments determined the production amount for the next period. In addition, this schedule can run for the long-term, which usually considers a 12-month period. It is clear that 12 -month period is very difficult to plan and deal with anticipation and uncertainty. The quality of this program determines the overall benefit of the manufacturing organizations. Thus offering a practicable and good implementation of the program is important.

In this chain, the first part related to crude oil has five production centers. In all production centers, one type of crude oil is produced, which combines all the input raw materials for these sectors. As can be seen from Figure 1, the produced crude oil is exported to the three demand centers: European Union, OECD Asia and Non OECD Asia, or it is used by refineries. There are nine production centers in the refinery sector each of which converts raw materials from crude oil sector into six types of products: Naphtha, Gasoline Engine, Kerosene, Gas oil, Fuel oil, and Propylene. These materials are used in the petrochemical sector or sent to the 11 possible demand centers $\mathrm{mr} 1, \mathrm{mr} 2, \mathrm{mr} 3, \mathrm{mr} 4, \mathrm{mr} 5$, mr6, mr7, mr8, mr9, mr10, and mr11. The propylene doesn't have any demands from out of the chain, and only naphtha and propylene are used in the petrochemical sector. Naphtha is used by Mahshahr, Assaluyeh and Shazand-Arak production centers and propylene is used by Shiraz and Tabriz production centers. The products produced in the petrochemical sector are as follows: Ethan, Propane, Ethylene, Heavy naphtha cut, Benzene, Ammonia, Urea, and Methanol.

There are three demand centers for petrochemical products containing: $\mathrm{mp} 1, \mathrm{mp} 2, \mathrm{mp} 3$.
Benzene is used by downstream chemical sector. There are three demand centers in the downstream chemical sector, md1, md2, md3, also a product, Styrene, is produced in each production center. Styrene is used directly in three existing demand centers.

\section{Deterministic mathematical model}

A deterministic model will be presented in this section. Before offering deterministic mathematical optimization model for crude oil supply chain network, the definition of following expressions are important.

Planning horizon: indicates a period of time when the company tries to predict product demands and allotment. The planning horizon is usually separated into some periods in which the program items are run.

Demand sources: markets and distribution centers.

Demand: it is product size requirements for different client demands of certain periods of time.

Lost demand: the volume of products that could not be sent to the demand authorities for meeting the demand. Backlog: it is additional demanded products (and met) that are not met until then. Some or all of the backlog may be sent in later periods. A volume of backlog that are not met during the planning horizon, counted as lost demand.

\subsection{The objective function}

The objective function intends to optimize crude oil resources with minimization the total cost of production and logistics as well as lost demands and backlog penalties and with maximization of profit. The objective function for deterministic model can be expressed in the following equation.

$$
Z=\min \left\{z^{C}, z^{R}, z^{P}, z^{D}\right\} .
$$

Here $z^{C}, z^{R}, z^{P}$ and $z^{D}$ are the profit on crude oil, refineries, petrochemicals and downstream sectors respectively. $z^{C}, z^{P}$ and $z^{D}$ are expressed by equation (2) and $z^{R}$ by equation (3).

$$
\begin{gathered}
z^{s}=\sum_{t \in T} \sum_{i \in P^{s}}\left\{\begin{array}{l}
\sum_{k \in I^{s}}\left[C V_{i}^{s, k} V_{i, t}^{s, k}+C S_{i}^{s, k} S_{i, t}^{s, k}\right] \\
+\sum_{j \in M^{s}}\left[C L_{i}^{s} L_{i, j, t}^{s}+C B_{i}^{s} B_{i, j, t}^{s}\right] \\
+\sum_{k \in I^{s}} \sum_{j \in M^{s}}\left[C F_{i, j}^{s} F_{i, j, t}^{s, k}-P_{i, t}^{s} F_{i, j, t}^{s, k}\right]
\end{array}\right\} s \in\{C, P, D\} . \\
z^{R}=\sum_{t \in \mathrm{T}}\left\{\begin{array}{l}
\sum_{i \in P^{C}} \sum_{k \in I^{C}}\left[C C_{i}^{R, k} V C_{i, t}^{R, k}\right] \\
+\sum_{i \in P^{R}}\left\{\begin{array}{l}
\sum_{k \in I^{s}}\left[C S_{i}^{R, k} S_{i, t}^{R, k}\right] \\
+\sum_{j \in M^{s}}\left[C L_{i}^{R} L_{i, j, t}^{R}+C B_{i}^{R} B_{i, j, t}^{R}\right] \\
+\sum_{k \in I^{R}} \sum_{j \in M^{s}}\left[C F_{i, j}^{R} F_{i, j, t}^{R, k}-P_{i, t}^{R} F_{i, j, t}^{R, k}\right.
\end{array}\right\}
\end{array}\right\}
\end{gathered}
$$


Equation (2) includes 6 items: costs of production, warehousing, transportation, lost demands, backlog and profit. Decision variables in equation (2) are production values $V_{i, t}^{s, k}$, the stored values in the warehouse $S_{i, t}^{s, k}$, posted sources to the demand clients $F_{i, j, t}^{s, k}$, lost demands, $L_{i, j, t}^{s}$, backlog values, $B_{i, j, t}^{s}$.

Refineries production costs are highly dependent on crude mix and the main challenge is the maximization of profit from each input barrel of the crude oil. The crude mix cost with the first item has been mentioned in equation (3).

\subsection{Constraints}

\subsubsection{Material flow balance}

Materials balance for crude oil section:

$$
\begin{aligned}
\sum_{k \in I^{C}}\left(S_{i, t-1}^{C, k}+V_{i, t}^{C, k}\right)= & \sum_{k \in I^{C}} \sum_{j \in M^{C}} F_{i, j, t}^{C, k}+\sum_{k \in I^{R}} V C_{i, t}^{R, k} \\
& +\sum_{k \in I^{R}} S_{i, t}^{C, k} \quad \forall i \in P^{C}, t \in T .
\end{aligned}
$$

Materials balance for the refinery products:

$$
\begin{gathered}
S_{i, t-1}^{R, k}+V_{i, t}^{R, k}=\sum_{j \in M^{R}} F_{i, j, t}^{R, k}+£_{i}^{R, k} V P_{i, t}^{R, k}+S_{i, t}^{R, k} \\
\forall i \in P^{R}, t \in T, k \in I^{R} .
\end{gathered}
$$

Materials balance for the petrochemical products:

$$
\begin{gathered}
S_{i, t-1}^{R, k}+V_{i, t}^{R, k}=\sum_{j \in M^{R}} F_{i, j, t}^{R, k}+£_{i}^{R, k} V P_{i, t}^{R, k}+S_{i, t}^{R, k} \\
\forall i \in P^{R}, t \in T, k \in I^{R} .
\end{gathered}
$$

Materials balance for the downstream products:

$$
\begin{gathered}
S_{i, t-1}^{D, k}+V_{i, t}^{D, k}=\sum_{j \in M^{D}} F_{i, j, t}^{D, k}+S_{i, t}^{D, k} \\
\forall i \in P^{D}, t \in T, k \in I^{D} .
\end{gathered}
$$

In equations (5)-(7) it is assumed that storehouse and common market facilities are used for all factories.

\subsubsection{Demand balance}

The demand constraints of market can be expressed by the following equations for four business sectors:

$$
\begin{gathered}
B_{i, j, t-1}^{s}+D_{i, j, t}^{s}=\sum_{k \in I^{s}} F_{i, j, t}^{s, k}+L_{i, j, t}^{s}+B_{i, j, t}^{s} \\
\forall s \in\{C, R, P, D\}, \forall i \in P^{s}, j \in M^{s}, t \in T .
\end{gathered}
$$

The quantity of lost demand $L_{i, j, t}^{s}$ is as follows:

$$
\begin{gathered}
L_{i, j, t}^{s}=\delta_{j}^{s}\left(B_{i, j, t-1}^{s}+D_{i, j, t}^{s}-\sum_{k \in I^{s}} F_{i, j, t}^{s, k}\right) \\
\forall s \in\{C, R, P, D\}, \forall i \in P^{s}, j \in M^{s}, t \in T .
\end{gathered}
$$

\subsubsection{Crude oil production constraints}

$$
V_{\min }^{C, k} \leq \sum_{i \in P^{C}} \sum_{k \in I^{C}} V_{i, t}^{C, k} \leq V_{\max }^{C, k} \quad \forall t \in T .
$$

\subsubsection{Producing products}

Equation (11) defines the quantities of refined products that may be produced from a specific kind of crude oil:

$$
V_{i, t}^{R, k}=\sum_{k \in I^{R}}\left(\gamma_{i, j}^{R, k} V C_{j, t}^{R, k}\right) \quad \forall i \in P^{R}, k \in I^{R}, t \in T .
$$

Producing of petrochemical products are defined with respect to the refined products as:

$$
V_{i, t}^{P, k}=\sum_{j \in P^{R}} \sum_{l \in I^{R}} \gamma_{i, j}^{P, k} V D_{j, t}^{P, l} \quad \forall i \in P^{P}, k \in I^{P}, t \in T .
$$

Producing of downstream products are defined with respect to the petrochemical products as:

$$
V_{i, t}^{D, k}=\sum_{j \in P^{P}} \sum_{l \in I^{P}} \gamma_{i, j}^{D, k} V D_{j, t}^{P, l} \quad \forall i \in P^{D}, k \in I^{D}, t \in T .
$$

\subsubsection{Refinery throughput}

Bounds on total yield's crude oil in the refineries are expressed as:

$$
V C_{\min }^{R, k, t} \leq \sum_{i \in P^{C}} V C_{i, t}^{R, k} \leq V C_{\max }^{R, k, t} \quad \forall k \in I^{R}, t \in T .
$$

\subsubsection{Petrochemicals and downstream chemicals production bounds}

Upper bounds for the production quantities of petrochemical and downstream chemical products:

$$
V_{i, t}^{P, k} \leq V_{i, \max }^{P, k} \quad \forall i \in P^{P}, k \in I^{P}, t \in T .
$$

$$
V_{i, t}^{D, k} \leq V_{i, \max }^{D, k} \quad \forall i \in P^{D}, k \in I^{D}, t \in T
$$

\subsubsection{Storehouses capacities}

$$
\sum_{k \in I^{s}} \sum_{i \in P^{s}} S_{i, t}^{s, k} \leq S_{\max }^{s} \quad \forall s \in\{C, R, P, D\}, t \in T .
$$

\section{Robust optimization mathematical model}

Many countries, including Iran, have an oil-dependent economy. Thereupon, income fluctuations in such countries can greatly affect the national economy and results in political challenges. In order to provide an efficient production plan based on the concerned problem assumptions, a model has to be elaborated that can meet all the limitations of the 
studied problems at the same time. Since in the oil market the demands can be accompanied with uncertainties and this issue may impose high cost to decision maker, the model should be formed in the way which can conveniently control the violation cost and average performance of the system. Another issue here is the risk aversion nature of the net profit in such supply chain. High tolerances in net profit can cause instability in the economy of a country. Therefore, the proposed model should also able to control the performance variance under different possible values of uncertain parameters to avoid the relevant risks. The solution of an optimization problem is called to be robust if it remains feasible for almost all possible values of uncertain parameters (feasibility robustness) and the relevant objective function value remains close to optimal value for almost all possible values of uncertain parameters (optimality robustness) [25]. Here a scenario-based twostage robust optimization model proposed by $\mathrm{Yu}$ and $\mathrm{Li}$ [26] that it is modified version of Mulvey et al. [27] model is applied to ensure the robustness of the model solution. Compared to different robust programming approaches such as the methods proposed by Pishvaee et al. [25], Bertsimas and Sim [28] and Ben-Tal and Nemirovski [29], the scenario-based robust optimization method has significant advantages. This method can use both the subjective and objective information to model the uncertain parameters via scenarios which is more convenient compared to forming probability or possibility distributions. Also, this method is able to form a reasonable balance between average performance, feasibility robustness and optimality robustness and therefore, achieve a more practical solution compared to worst-case methods which impose high conservatism to decision maker.

The proposed model tries to increase the average benefits of all the scenarios (average system's performance) while reducing the amount of variance (optimality robustness) and controlling the constraint violation cost (feasibility robustness).

In the developed model $h_{s}$ represents the violation unit cost of constraints which controls the feasibility robustness. In addition $n \%$ and $(1-n) \%$ importance weights are given to average performance and the variance, respectively. The probability of each scenario is denoted by $p_{w}$, which $w$ represents the index of scenarios. Moreover, $\mathrm{q}_{\mathrm{s}, \mathrm{w}}^{+}, \mathrm{q}_{\mathrm{s}, \mathrm{w}}^{-}$ denote the positive and negative deviation of the value of the objective function under each scenario from the average performance and $\phi_{s}^{+}, \phi_{s}^{-}$denote the amount of positive and negative constraint violation, respectively.

In the petroleum company problem presented in this study, the first-stage decisions correspond to the production profile of each type of crude oil during the planning horizon. Second-stage decisions consist of quantities of refinery and petrochemical products produced as well as quantities of all shipments, storage, lost demands and backlogs for different scenarios.

First-stage decisions are crude oil production quantities $V_{i, t}^{c, k}$. Hence, the second-stage variables include production quantities of refinery products, petrochemicals and downstream petrochemicals $\left(V_{i, t}^{s, k, w}, s \in\{R, P, D\}\right)$, allocated quantities for further processing $\left(V C_{i, t}^{R, k, w}, V P_{i, t}^{R, k, w}\right.$ and
$\left.V D_{i, t}^{P, k, w}\right)$, as well as quantities shipped, stored, lost demand, and backlog $\left(F_{i, j, t}^{s, k, w}, S_{i, t}^{s, k, w}, L_{i, j, t}^{s, w}, B_{i, j, t}^{s, w}, s \in\{C, R, P, \mathrm{D}\}\right)$. The two sources of uncertainty considered in this study changed in market demand for crude oil and the market prices of crude oil, refinery products, petrochemicals and downstream chemicals produced by the petroleum organization.

\subsection{The objective function in a state of uncertainty}

The objective is to reduce the net loss or increase the net profit that can be expressed as follows:

$$
Z=\min \left\{z^{C}, z^{R}, z^{P}, z^{D}\right\} .
$$

Here $z^{C}, z^{R}, z^{P}$ and $z^{D}$ show the profit of crude oil, refineries, petrochemical and downstream sectors respectively, which together achieved with regard to all scenarios come. In all these sections the prices are uncertain.

Objective function of crude oil in a state of uncertainty can be expressed as follows:

$$
\begin{aligned}
& z^{c}=n \times \sum_{t \in T} \sum_{i \in P^{c}}\left\{\begin{array}{l}
\sum_{k \in I^{c}}\left(\begin{array}{c}
C V_{i}^{c, k} V_{i, t}^{c, k}+ \\
\sum_{w=1,2,3,4,5} p(w) \times C S_{i}^{c, k} S_{i, t}^{c, k, w}
\end{array}\right) \\
+\sum_{j \in M^{c}} \sum_{w=1, \ldots, 5} p(w) \times\left(C L_{i}^{c} L_{i, j, t}^{c, w}+C B_{i}^{c} B_{i, j, t}^{c, w}\right) \\
+\sum_{k \in I^{c}} \sum_{j \in M^{c}} \sum_{w=1, \ldots, 5} p(w) \times\left(C F_{i, j}^{s} F_{i, j, t}^{c, k, w}-P_{i, t}^{c} F_{i, j, t}^{c, k, w}\right)
\end{array}\right\} \\
& +(1-n) \times\left(\sum_{w=1, \ldots, 5} p_{w} \times\left(q_{c, w}^{+}+q_{c, w}^{-}\right)+h_{c} \times \sum_{w} p_{w} \times\left(\varphi_{w}^{+}+\varphi_{w}^{-}\right)\right) .
\end{aligned}
$$

Objective function of petrochemical and downstream sector in a state of uncertainty can be expressed as follows:

$$
\begin{aligned}
z^{s}=n \times \sum_{w=1,2,3,4,5} \sum_{t \in T} \sum_{i \in P^{s}}\left\{\begin{array}{l}
\sum_{k \in I^{s}} p_{w} \times\left(C V_{i}^{s, k} V_{i, t}^{s, k, w}+C S_{i}^{s, k} S_{i, t}^{s, k, w}\right) \\
+\sum_{j \in M^{s}} p_{w} \times\left(C L_{i}^{s} L_{i, j, t}^{s, w}+C B_{i}^{s} B_{i, j, t}^{s, w}\right) \\
+\sum_{k \in I^{s}} \sum_{j \in M^{s}} p_{w} \times\left(C F_{i, j}^{s} F_{i, j, t}^{s, k, w}-P_{i, t}^{s} F_{i, j, t}^{s, k, w}\right)
\end{array}\right\} \\
+(1-n) \times\left(\sum_{w} p_{w} \times\left(q_{s, w}^{+}+q_{s, w}^{-}\right)+h_{s} \times \sum_{w} p_{w} \times\left(\varphi_{w}^{+}+\varphi_{w}^{-}\right)\right) .
\end{aligned}
$$

Objective function of the refinery in a state of uncertainty can be expressed as follows:

$$
\begin{aligned}
& z^{R}=n \times \sum_{w=1,2,3,4,5} p_{w} \times \sum_{t \in T}\left\{+\sum_{i \in P^{R}}\left\{\begin{array}{c}
\sum_{i \in P^{R}} \sum_{k \in I^{R}}\left(C C_{i}^{R, k} V C_{i, t}^{R, k, w}\right) \\
\sum_{k \in I^{R}}\left(C S_{i}^{R, k} S_{i, t}^{R, k, w}\right) \\
+\sum_{j \in M^{R}}\left(C L_{i}^{R} L_{i, j, t}^{R, w}+C B_{i}^{R} B_{i, j, t}^{R, w}\right) \\
+\sum_{k \in I^{R}} \sum_{j \in M^{R}}\left(C F_{i, j}^{R} F_{i, j, t}^{R, k, w}-P_{i, t}^{R} F_{i, j, t}^{R, k, w}\right)
\end{array}\right\}\right\} \\
& +(1-n) \times\left(\sum_{w} p_{w} \times\left(q_{r, w}^{+}+q_{r, w}^{-}\right)+h_{r} \times \sum_{w} p_{w} \times\left(\varphi_{w}^{+}+\varphi_{w}^{-}\right)\right) \text {. }
\end{aligned}
$$




\subsection{The constraints at state of uncertainty}

Variance constraints for crude oil sectors is expressed as follows:

$$
\begin{aligned}
& E\left(Z_{c}\right)=\sum_{t \in T} \sum_{i \in P^{c}}\left\{\begin{array}{l}
\sum_{k \in I^{c}}\left(C V_{i}^{c, k} V_{i, t}^{c, k}+\sum_{w=1,2,3,4,5} p(w) \times C S_{i}^{c, k} S_{i, t}^{c, k, w}\right) \\
+\sum_{j \in M^{c}} \sum_{w=1, \ldots, 5} p_{w} \times\left(C L_{i}^{c} L_{i, j, t}^{c, w}+C B_{i}^{c} B_{i, j, t}^{c, w}\right) \\
+\sum_{k \in I^{c}} \sum_{j \in M^{c}} \sum_{w=1, \ldots, 5} p_{w} \times\left(C F_{i, j}^{s} F_{i, j, t}^{c, k, w}-P_{i, t}^{c} c_{i, j, t}^{c, k, w}\right)
\end{array}\right\} . \\
& Z_{c, w}=\sum_{t \in T} \sum_{i \in P^{c}}\left\{\begin{array}{l}
\sum_{k \in I^{c}}\left(C V_{i}^{c, k} V_{i, t}^{c, k}+C S_{i}^{c, k} S_{i, t}^{c, k, w}\right) \\
+\sum_{j \in M^{c}}\left(C L_{i}^{c} L_{i, j, t}^{c, w}+C B_{i}^{c} B_{i, j, t}^{c, w}\right) \\
+\sum_{k \in I^{c}} \sum_{j \in M^{c}}\left(C F_{i, j}^{s} F_{i, j, t}^{c, k, w}-P_{i, t}^{c} F_{i, j, t}^{c, k, w}\right)
\end{array}\right\} . \\
& \left|Z_{c, w}-E\left(Z_{c}\right)\right|=q_{c, w}^{+}+q_{c, w}^{-} .
\end{aligned}
$$

$E\left(Z_{c}\right)$ is average net loss of crude oil and $Z_{c, w}$ is loss for each scenario in the crude oil. The quantity of crude oil production is a primary variable and independent from scenarios. This limitation shows the amount of difference between function benefit and the average. $c$ represents the supply chain crude oil sector.

Variance constraints for petrochemical and downstream sectors is expressed as follows:

$E\left(Z_{s}\right)=\sum_{w=1,2,3,4,5} \sum_{t \in T} \sum_{i \in P^{s}}\left\{\begin{array}{l}\sum_{k \in I^{s}} p_{w} \times\left(C V_{i}^{s, k} V_{i, t}^{s, k}+C S_{i}^{s, k} S_{i, t}^{s, k, w}\right) \\ +\sum_{j \in M^{s}} p_{w} \times\left(C L_{i}^{s} L_{i, j, t}^{s, w}+C B_{i}^{s} B_{i, j, t}^{s, w}\right) \\ +\sum_{k \in I^{s}} \sum_{j \in M^{s}} p_{w} \times\left(C F_{i, j}^{s} F_{i, j, t}^{s, k, w}-P_{i, t}^{s} F_{i, j, t}^{s, k, w}\right)\end{array}\right\}$.

$Z_{s, w}=\sum_{t \in T} \sum_{i \in P^{s}}\left\{\begin{array}{l}\sum_{k \in I^{s}}\left(C V_{i}^{s, k} V_{i, t}^{s, k}+C S_{i}^{s, k} S_{i, t}^{s, k, w}\right) \\ +\sum_{j \in M^{s}}\left(C L_{i}^{s} L_{i, j, t}^{s, w}+C B_{i}^{s} B_{i, j, t}^{s, w}\right) \\ +\sum_{k \in I^{s}} \sum_{j \in M^{s}}\left(C F_{i, j}^{s} F_{i, j, t}^{s, k, w}-P_{i, t}^{s} F_{i, j, t}^{s, k, w}\right.\end{array}\right\} s \in P, D$.

$$
\left|Z_{s, w}-E\left(Z_{s}\right)\right|=q_{s, w}^{+}+q_{s, w}^{-} .
$$

$E\left(Z_{s}\right)$ is average net loss for the petrochemical and downstream segments and $Z_{s, w}$ is the loss for each scenario in the petrochemical and downstream segments.
Variance constraints for refinery sectors is expressed as follows:

$E\left(Z_{r}\right)$ is average net loss for the refinery segments and $Z_{r, w}$ is the loss for each scenario in the refinery segments:

$E\left(Z_{r}\right)=\sum_{w=1,2,3,4,5} p_{w} \times \sum_{i \in T}\left\{\begin{array}{l}\sum_{i \in P^{R}} \sum_{k \in I^{R}}\left(C C_{i}^{R, k} V C_{i, t}^{R, k, w}\right)+ \\ \sum_{i \in P^{R}}\left(\begin{array}{l}\sum_{k \in I^{R}}\left(C S_{i}^{R, k} S_{i, t}^{R, k, w}\right) \\ +\sum_{j \in M^{R}}\left[C L_{i}^{R} L_{i, j, t}^{R, w}+C B_{i}^{R} B_{i, j, t}^{R, w}\right] \\ +\sum_{k \in I^{R}} \sum_{j \in M^{R}}\left[C F_{i, j}^{R} F_{i, j, t}^{R, k, w}-P_{i, t}^{R} F_{i, j, t}^{R, k, w}\right]\end{array}\right)\end{array}\right)$.

$$
Z_{r, w}=\sum_{t \in T}\left\{\begin{array}{l}
\sum_{i \in P^{R}} \sum_{k \in I^{R}}\left[C C_{i}^{R, k} V C_{i, t}^{R, k, w}\right]+ \\
\sum_{i \in P^{R}}\left\{\begin{array}{l}
\sum_{k \in I^{R}}\left[C S_{i}^{R, k} S_{i, t}^{R, k, w}\right] \\
+\sum_{j \in M^{R}}\left[C L_{i}^{R} L_{i, j, t}^{R, w}+C B_{i}^{R} B_{i, j, t}^{R, w}\right] \\
+\sum_{k \in I^{R}} \sum_{j \in M^{R}}\left[C F_{i, j}^{R} F_{i, j, t}^{R, k, w}-P_{i, t}^{R} F_{i, j, t}^{R, k, w}\right]
\end{array}\right\}
\end{array}\right\} .
$$

$$
\left|Z_{r, w}-E\left(Z_{r}\right)\right|=q_{r, w}^{+}+q_{r, w}^{-} .
$$

\subsection{Constraints material balance}

Material balance for crude oil in a state of uncertainty as follows:

$$
\sum_{k \in I^{C}}\left(S_{i, t-1}^{C, k, w}+V_{i, t}^{C, k, w}\right)=\sum_{k \in I^{C}} \sum_{j \in M^{C}} F_{i, j, t}^{C, k, w}+\sum_{k \in I^{R}} V C_{i, t}^{R, k, w}+\sum_{k \in I^{R}} S_{i, t}^{C, k, w}
$$

$$
\forall i \in P^{C}, t \in T, w=1, \ldots, 5 .
$$

Material balance for refinery products in a state of uncertainty as follows:

$$
\begin{gathered}
S_{i, t-1}^{R, k, w}+V_{i, t}^{R, k, w}=\sum_{j \in M^{R}} F_{i, j, t}^{R, k, w}+£_{i}^{R, k} V P_{i, t}^{R, k, w}+S_{i, t}^{R, k, w} \\
\forall i \in P^{R}, t \in T, k \in I^{R}, w=1, \ldots, 5 .
\end{gathered}
$$

Material balance for petrochemical products in a state of uncertainty as follows:

$$
\begin{gathered}
S_{(i, t-1)}^{(P, k, w)}+V_{(i, t)}^{(P, k, w)}=\sum_{j \in M^{P}} F_{i, j, t}^{P, k, w}+£_{i}^{P, k, w} V D_{i, t}^{P, k, w}+S_{i, t}^{P, k, w} \\
\forall i \in P^{P}, t \in T, k \in I^{P}, w=1, \ldots, 5 .
\end{gathered}
$$


Material balance for downstream products in a state of uncertainty as follows:

$$
\begin{gathered}
S_{i, t-1}^{D, k, w}+V_{i, t}^{D, k, w}=\sum_{j \in M^{D}} F_{i, j, t}^{D, k, w}+S_{i, t}^{D, k, w} \\
\forall i \in P^{D}, t \in T, k \in I^{D}, w=1, \ldots, 5 .
\end{gathered}
$$

In this equation assumes that all factories have common storage and market facilities.

\subsection{Demand balance in a state of uncertainty}

Demand market constraints can be expressed by the following equations to four business sections. In this part, the uncertainty of demand for each scenario is specified by $\propto_{w}$ factor:

$$
\begin{gathered}
B_{i, j, t-1}^{s, w}+\propto_{w} \times D_{i, j, t}^{s}=\sum_{k \in I^{s}} F_{i, j, t}^{s, k, w}+L_{i, j, t}^{s, w}+B_{i, j, t}^{s, w}+\varphi s 1(w)+\varphi s 1(w) \\
\forall s \in\{C, R, P, D\}, \forall i \in P^{s}, j \in M^{s}, t \in T, w=1, \ldots, 5 .
\end{gathered}
$$

The amount of lost demand $\boldsymbol{L}_{i, j, t}^{s}$ in a state of uncertainty are as follows:

$$
S_{i, t-1}^{D, k, w}+V_{i, t}^{D, k, w}=\sum_{j \in M^{D}} F_{i, j, t}^{D, k, w}+S_{i, t}^{D, k, w}
$$

$\forall s \in\{C, R, P, D\}, \forall i \in P^{s}, j \in M^{s}, t \in T, w=1, \ldots, 5$.

Crude oil constraints production in a state of uncertainty are as follows:

$$
\begin{gathered}
V_{\text {min }}^{C, k} \leq \sum_{i \in P^{C}} \sum_{k \in I^{C}} V_{i, t}^{C, k, w} \leq V_{\max }^{C, k} \\
\forall t \in T, w=1, \ldots, 5 .
\end{gathered}
$$

\subsection{Production constraints in a state of uncertainty}

The following equation defines the value of refined products, which may be of a certain type of crude oil:

$$
\begin{aligned}
& V_{i, t}^{R, k, w}=\sum_{k \in I^{R}}\left(\gamma_{i, j}^{R, k} V C_{j, t}^{R, k, w}\right) \\
& \quad \forall i \in P^{R}, k \in I^{R}, t \in T, w=1, \ldots, 5 .
\end{aligned}
$$

Production of petrochemical products in relation to refined products, will be as follows:

$$
\begin{aligned}
& V_{i, t}^{R, k, w}=\sum_{k \in I^{R}}\left(\gamma_{i, j}^{R, k} V C_{j, t}^{R, k, w}\right) \\
& \quad \forall i \in P^{P}, k \in I^{P}, t \in T, w=1, \ldots, 5 .
\end{aligned}
$$

The production of downstream products in relation to petroleum products, is expressed as follows:

$$
\begin{gathered}
V_{i, t}^{D, k, w}=\sum_{j \in P^{P}} \sum_{l \in I^{P}} \gamma_{i, j}^{D, k} V D_{j, t}^{P, l, w} \\
\forall i \in P^{D}, k \in I^{D}, t \in T, w=1, \ldots, 5 .
\end{gathered}
$$

The total efficiency range of crude oil in refineries is as follows:

$$
\begin{gathered}
V C_{\min }^{R, k, t} \leq \sum_{i \in P^{C}} V C_{i, t}^{R, k, w} \leq V C_{\max }^{R, k, t} \\
\forall k \in I^{R}, t \in T, w=1, \ldots, 5 .
\end{gathered}
$$

Range of petrochemicals and chemical downstream products explained as follow:

$$
\begin{aligned}
& V_{i, t}^{P, k, w} \leq V_{i, \max }^{P, k} \\
& \forall i \in P^{P}, k \in I^{P}, t \in T, w=1, \ldots, 5 . \\
& V_{i, t}^{D, k, w} \leq V_{i, \max }^{D, k} \\
& \quad \forall i \in P^{D}, k \in I^{D}, t \in T, w=1, \ldots, 5 .
\end{aligned}
$$

Storage capacity explained as follow:

$$
\begin{aligned}
& \sum_{k \in I^{s}} \sum_{i \in P^{s}} S_{i, t}^{s, k, w} \leq S_{\max }^{s} \\
& \quad \forall s \in\{C, R, P, D\}, t \in T, w=1, \ldots, 5 .
\end{aligned}
$$

\section{The case of Iran's petroleum supply chain}

In this part, the offered model will be reviewed in certain mode by the country's crude oil supply chain data. The costs include the cost of warehousing, manufacturing cost, the cost of the backlog, the cost of lost demand, and transmission cost to demand centers. The cost of buying and selling between the supply chain is not considered because the cost of sales per unit of goods is equal to the cost of buying it in the next section. In the following, the demands and different cost of products have been considered for 12 months. Figure 2 shows the demand for various products for a 12-month period and Figure 3 shows the price of refined products for a period of 12 months.

As previously mentioned, in the energy market, particularly oil and gas, the demands and oil price have usually had fluctuations and uncertainties in different periods for various reasons as political, economic, etc. As a consequence, the estimation of producing quantity in different situations is very important for planners, in the way that the loss of this uncertainties is minimized. Therefore, the scenarios for demands and prices should always be predicted, and the most probable of them must be selected; furthermore, a suitable model have to be designed for solving the problem. In this issue five different scenarios are considered. Table 2 illustrates the five scenarios (the initial demand $\mathrm{D}$ and the initial price $\mathrm{P}$ ).

\section{Results and discussion}

Both the deterministic and stochastic formulations described above are Linear Programs (LP), which are 


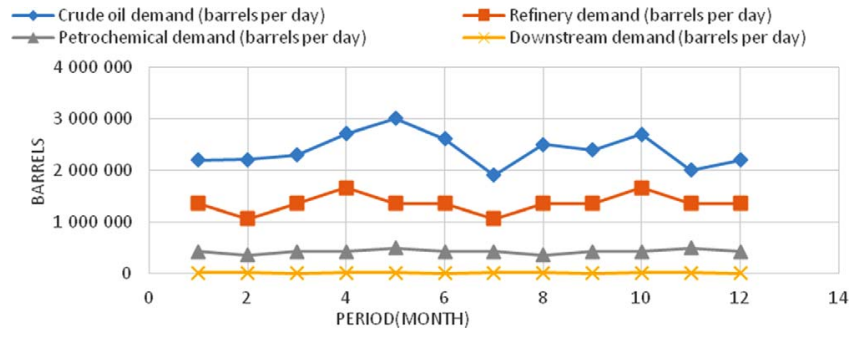

Fig. 2. The demand for various products for a 12-month period.

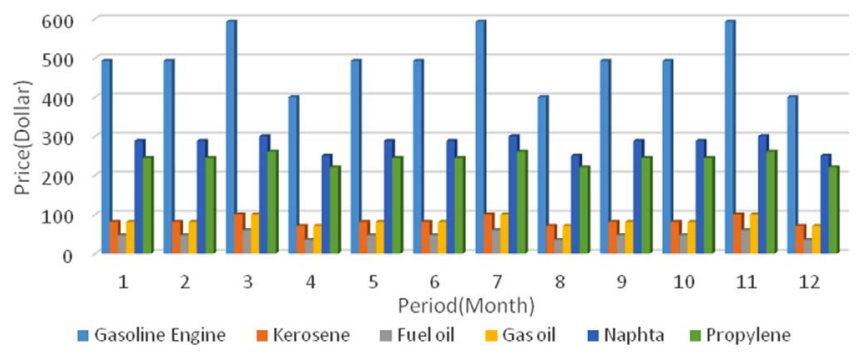

Fig. 3. Price of refined products for a period of 12 months.

implemented and solved using GAMS. The solver used is CPLEX 12.6. For the supply chain network example pre-

Table 2. Price and demand scenarios in the case of uncertainty.

\begin{tabular}{lcc}
\hline Scenario $(\mathrm{w})$ & Prices & Demand \\
\hline 1 & $0.8 \times \mathrm{P}$ & $\left(\propto_{1}=1.2\right) \times \mathrm{D}$ \\
2 & $0.9 \times \mathrm{P}$ & $\left(\propto_{2}=1.1\right) \times \mathrm{D}$ \\
3 & $\mathrm{P}$ & $\left(\propto_{3}=1\right) \times \mathrm{D}$ \\
4 & $1.1 \times \mathrm{P}$ & $\left(\propto_{4}=0.9\right) \times \mathrm{D}$ \\
5 & $1.2 \times \mathrm{P}$ & $\left(\propto_{1}=0.8\right) \times \mathrm{D}$ \\
\hline
\end{tabular}

sented in the following section, the deterministic cases involve solving 5849 equations with 14369 variables and 89104 non-zero elements. The nondeterministic cases involve solving 27019 equations with 69535 variables and 742858 non-zero elements.

\subsection{The state of certainty}

Figure 4 shows the lack of demand lost in each period to meet the demands for crude oil. Here net profit of the whole supply chain for four parts (i.e. crude oil, refinery, petrochemical and downstream) is determined. It should be noted that the profit from the difference between revenue and expenditure chain is different.

Figure 5 shows a net profit of four sections of petroleum supply chain. Figure 6 shows the percentage contribution of

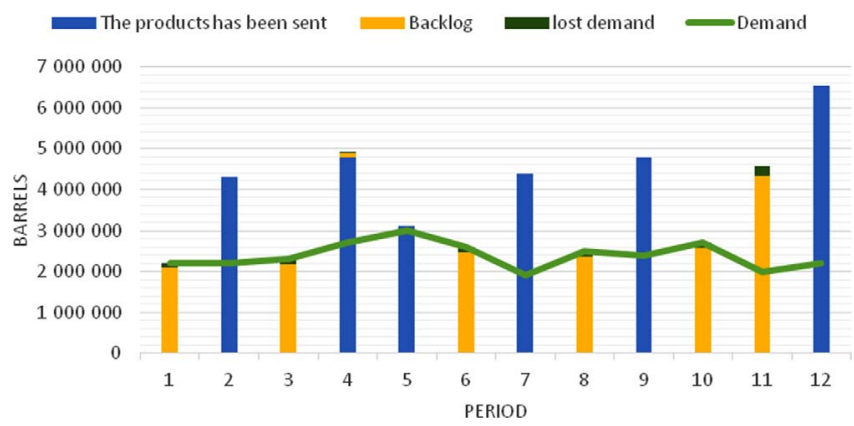

Fig. 4. Lack of demand lost in each periods to meet the demands for crude oil.

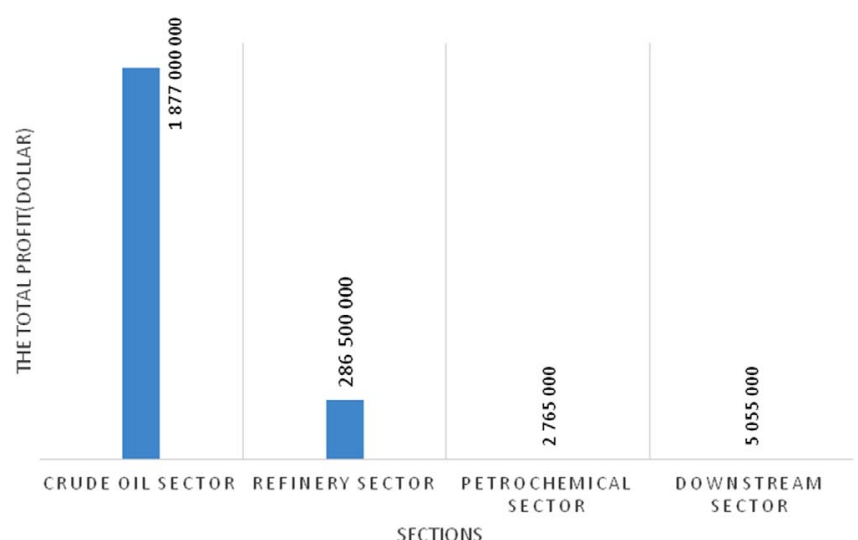

Fig. 5. Net profit of four sections of petroleum supply chain (Dollar).

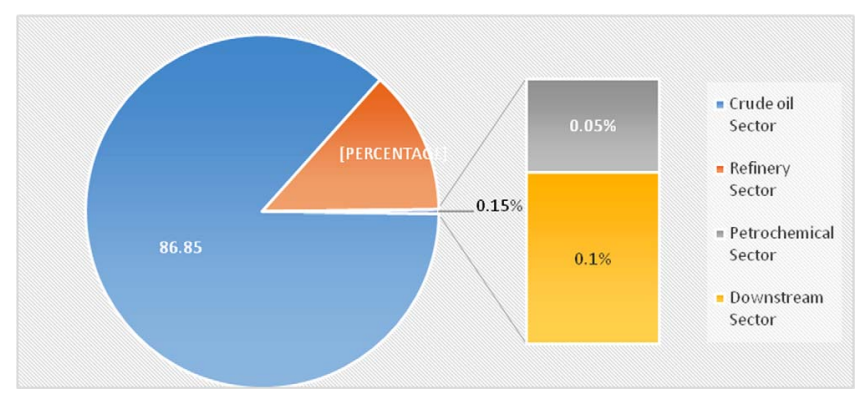

Fig. 6. The share of profit four sections of supply chain Petroleum.

each of these sectors to benefit the entire petroleum supply chain.

The total cost of the petroleum supply chain is imposed in this 12 periods are: production cost, maintenance cost, backlog cost, lost demand cost, shipping cost. The supply chain revenue is the sales revenue. The costs and revenues of petrochemical products to 12 specifies the period are set out in Figure 7. As it stands, backlog cost accounted for the highest cost, and this amount increases in each 


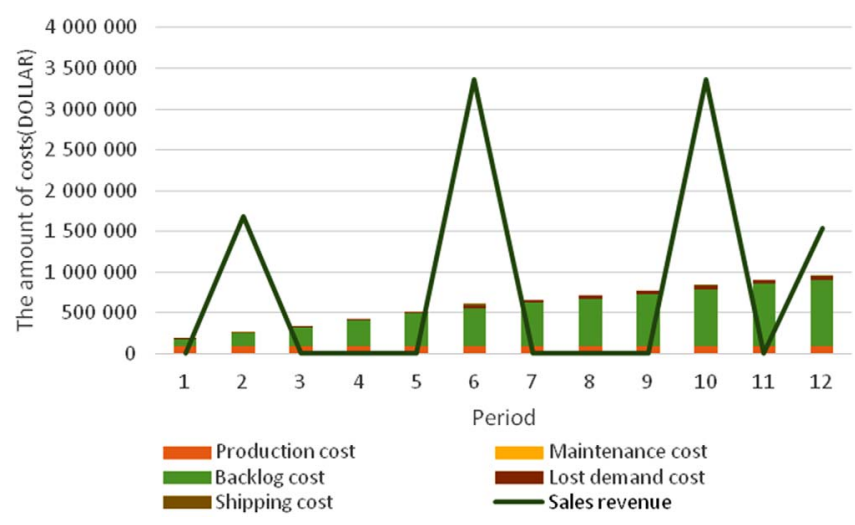

Fig. 7. The costs and revenues of petrochemical products to 12 specifies the period.

Table 3. Probability of each scenario.

\begin{tabular}{lccccc}
\hline Scenarios & 1 & \multicolumn{1}{c}{2} & 3 & 4 & 5 \\
\hline Probability (Mode 1) & 0.1 & 0.15 & 0.5 & 0.15 & 0.1 \\
Probability (Mode 2) & 0.3 & 0.15 & 0.1 & 0.15 & 0.3 \\
Probability (Mode 3) & 0.2 & 0.2 & 0.2 & 0.2 & 0.2 \\
\hline
\end{tabular}

Table 4. The cost per unit constant violations.

\begin{tabular}{lcccc}
\hline $\begin{array}{l}\text { Modes } \\
\text { (Dollar) }\end{array}$ & $\begin{array}{c}\text { Crude } \\
\text { oil }\end{array}$ & Refinery & Petrochemical & Downstream \\
\hline Mode 1 & 1000000 & 500000 & 600000 & 500000 \\
Mode 2 & 200 & 100 & 120 & 100 \\
Mode 3 & 10 & 5 & 6 & 5 \\
Mode 4 & 0.05 & 0.025 & 0.03 & 0.025 \\
Mode 5 & 0 & 0 & 0 & 0 \\
\hline
\end{tabular}

period. Backlog cost may be by reason of a lack of crude oil and refined products sectors. We have sales revenue only in periods of $2,6,10$ and 12 .

\subsection{The state of uncertainty}

Here the problem has been raised by regarding to the five scenarios, the following criteria will be examined. Table 3 shows each of the scenarios probability in three modes. Table 4 shows the cost of constraints violation for each of the petroleum supply chain in five modes. Table 5 shows the importance of variance and mean in the five modes.

Figure 8 shows average net profit chain for various scenarios in case of uncertainty, When the probability of all scenarios is equal to 0.2 (Mode 3 ) and the cost of constraints violation is in Mode 3 and the importance of the mean and variance is in Mode 1 . If the issue is certain, the value of total net income is shown. As shown in Figures 8 and 9 as the problem is faced with an uncertainty, the amount
Table 5. The cost per unit constant violations of restrictions by other factors.

\begin{tabular}{lcc}
\hline Modes & Average & Variance \\
\hline Mode 1 & 0 & 1 \\
Mode 2 & 0.1 & 0.9 \\
Mode 3 & 0.5 & 0.5 \\
Mode 4 & 0.9 & 0.1 \\
Mode 5 & 1 & 0 \\
\hline
\end{tabular}

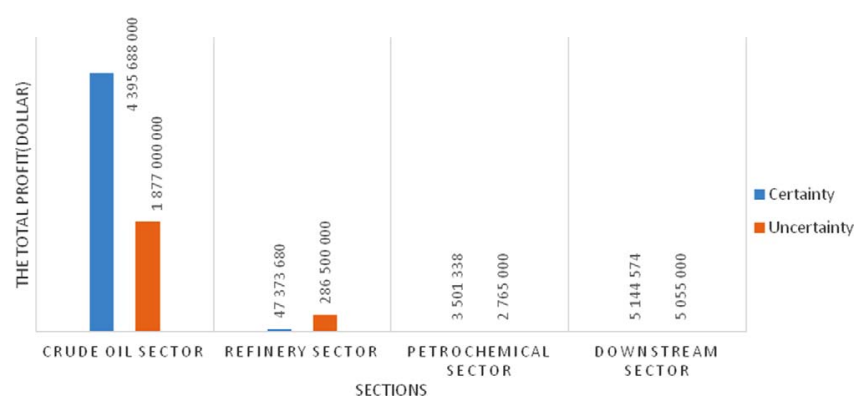

Fig. 8. Compared to a net profit of four parts petroleum supply chain in terms of certainty vs. uncertainty.

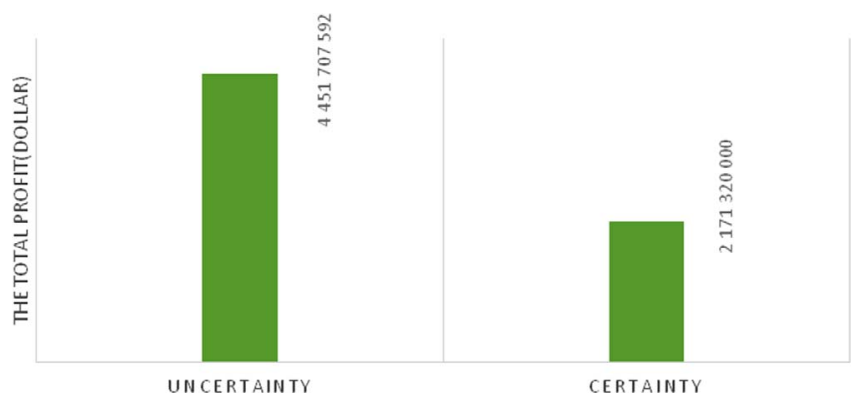

Fig. 9. The net profit of the entire supply chain in a state of uncertainty $v s$. certainty.

of profitability is much more than in certainty mode. Figure 9 shows the net profit of the entire supply chain in a state of uncertainty vs. certainty.

\subsection{Analysis of different modes in uncertainty}

The probability of different scenarios could affect the profitability of the entire petroleum supply chain. Three modes are considered for probability of different scenarios in which once every five scenarios have same probability and in other two modes, the probability of each scenario is different. Figure 10 shows three different modes of the probabilities.

In Figure 11 the profitability of each of the considered scenarios can be observed. The results indicated that the change in the value of scenarios' probability has a low impact on the average value of profit under scenarios. However, when the scenario 3 is more probable, the average profit increases more than the other modes. In the case of 


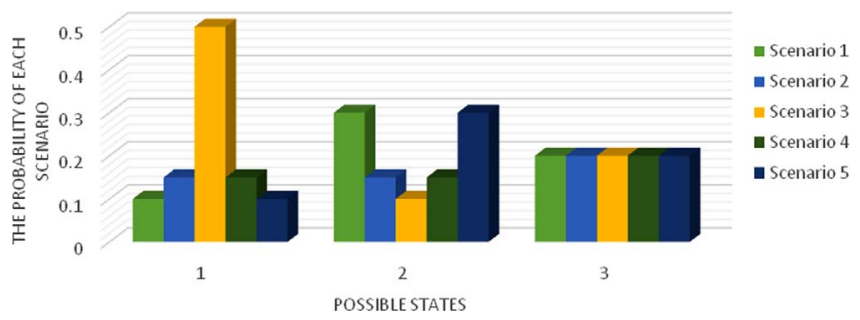

Fig. 10. Different modes of scenarios probability.

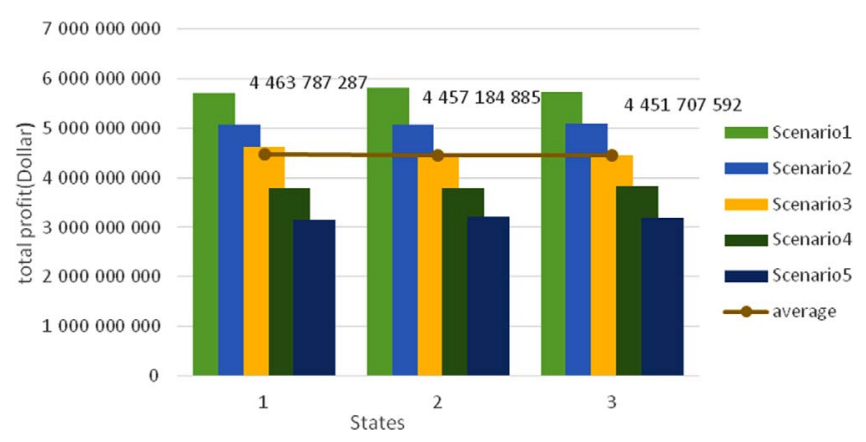

Fig. 11. The total profit of the supply chain under different probability for scenarios.

same probability for scenarios, the total profit is reduced. Therefore, it can be concluded that the average total profit is somehow robust according to changes in the probability of scenarios.

As previously mentioned, the amount of constraint violation could cause some costs for the supply chain. However, since violation cost avoids the probability of infeasibility it can also increase the total profit under real-life situation. For this purpose, five different modes for the cost of constraint violation are intended. By examining these cases, the profitability can be increased under different modes. In case of constraint violation, as shown in Table 4, the cost is extremely high. It can be seen from Figure 12 that when the violation cost is high the profitability of all scenarios as well as the average total profit reduced (see the results of Mode 1), but when violation cost is low (i.e. the risk is low) the total profit increases (cases 2 and 5).

In different conditions the importance of average and variance of the supply chain performance can be varied. So the five different modes in which the importance of the average and variance of interest have investigated to examine the profitability of the entire chain. According to Table 5 in Modes 1 and 2 the coefficient of variation (i.e., importance weight) is high, but, in the Mode 3 the important weights are the same and the importance weight of the average performance is high in the Modes 4 and 5 . As it can be seen in Figure 13 when the importance weight of the average is zero, the objective function reduces since only the variance term in the objective function is activated. Therefore, the profitability of different scenarios occurs at a very low value and the variance would be zero (Mode 1). When the importance of both average and variance terms are the same, the most desirable result is achieved,

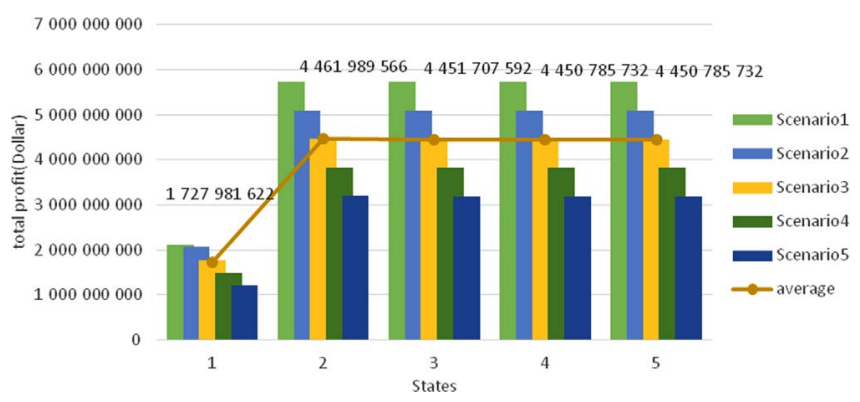

Fig. 12. The amount of net profit and average profit of each scenario with respect to the cost per unit constant violation of limits and conditions.

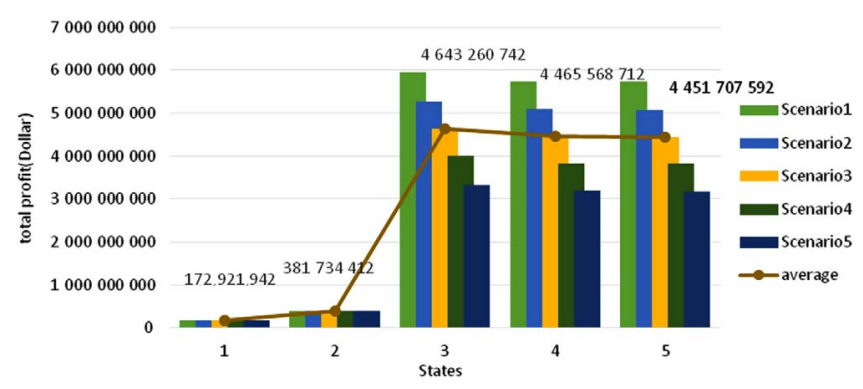

Fig. 13. The amount of net profit and average profit of each scenario according to the mean and variance of the response scenarios.

i.e., the low amount of variance and high value for average (Mode 3). In the case of Modes 4 and 5 , that the importance of average has gone up not only the total profit is not increased, but also the average is also facing decline, while the variance has not changed. Therefore, the state 3 can be considered as a more favorable condition.

\section{Conclusion}

Always the demands of different energies, particularly oil, have a lot of fluctuations. So demands cannot be estimated precisely. Also, the cost of various products derived from crude oil is affected by different factors which in each period has uncertainty. In this study, we tried to examine the situation on the oil and gas markets and taking into account the existing uncertainty to price and market demand, offer a model that is based on linear programming with regard to the different scenarios, offer the optimal solution for the profitability of the various sectors of petroleum supply chain. In this study we also examined the risk appetite in this area and it was found that as the importance of variance and average was closer to them, the profit would be higher. This is on the condition that one of the risks is in the Middle conditions. But much more risk-averse will be less profit and also at high risks will decrease the average profit compared to the middle. The impact of probability of each scenario has little impact on the ultimate answer, but the changes in the cost constraint violation in some circumstances could 
have a great impact on the ultimate answer. As the cost of limitation violation is higher, the profitability becomes less and as this cost is lower, model can apply a better solution to the problem of gain by violations of restrictions. The profitability when uncertainty is considered often more than the case when we consider the problem as certain. For future studies can be carried out much more with considering the optimal solution for each scenario and comparing it with the questions each scenario in the effect of other scenarios and minimizing the distance between them (or minimize the relative regret). You can always consider the demand and prices as continuum and solve the problem with Robust Convex Optimization and Robust Fuzzy Optimization. Also you can complete the chain and its development for other sections of energy and examine the profitability and reduce energy losses in a country. A recommended avenue for future research is to study Enhanced Oil Recovery (EOR) technology. The successful application of t EOR technology can have a significant impact on the energy conservation program of any oil producing country [30].

\section{References}

1 Bauquis P.R. (2001) A reappraisal of energy supply and demand in 2050, Oil Gas Sci. Technol. - Rev. IFP Energies nouvelles 56, 4, 389-402.

2 Sahebi H., Nickel S., Ashayeri J. (2014) Strategic and tactical mathematical programming models within the crude oil supply chain context - A review, Comput. Chem. Eng. 68, 56-77.

3 La Londe B.J., Masters J.M. (1994) Emerging logistics strategies: Blueprints for the next century, Int. J. Phys. Distrib. Logist. Manag. 24, 7, 35-47.

4 Mentzer J.T., DeWitt W., Keebler J.S., Min S.H., Nix N.W., Smith C.D., Zacharia Z.G. (2001) Defining supply chain management, JBL 22, 2, 1-25.

5 Neiro S.M., Pinto J.M. (2004) A general modeling framework for the operational planning of petroleum supply chains, Comput. Chem. Eng. 28, 6, 871-896.

6 MirHassani S. (2008) An operational planning model for petroleum products logistics under uncertainty, Appl. Math. Comput. 196, 2, 744-751.

7 Oliveira F., Gupta V., Hamacher S., Grossmann I.E. (2013) A Lagrangean decomposition approach for oil supply chain investment planning under uncertainty with risk considerations, Comput. Chem. Eng. 50, 184-195.

8 Oliveira F., Grossmann I.E., Hamacher S. (2014) Accelerating Benders stochastic decomposition for the optimization under uncertainty of the petroleum product supply chain, Comput. Oper. Res. 49, 47-58.

9 Fernandes L.J., Relvas S., Barbosa-Póvoa A.P. (2013) Strategic network design of downstream petroleum supply chains: single versus multi-entity participation, Chem. Eng. Res. Des. 91, 8, 1557-1587.

10 Chen J., Lu J., Qi S. (2010) Transportation network optimization of import crude oil in China based on minimum logistics cost, Paper presented at the Emergency Management and Management Sciences (ICEMMS), 2010 IEEE International Conference on Emergency Management.

11 Gupta V., Grossmann I.E. (2012) An efficient multiperiod MINLP model for optimal planning of offshore oil and gas field infrastructure, Ind. Eng. Chem. Res. 51, 19, 6823-6840.

12 Sahebi H., Nickel S. (2014) Offshore oil network design with transportation alternatives, Eur. J. Ind. Eng. 8, 6, 739-761.

13 Elsholkami M., Elkamel A. (2014) Design and operation of a sulfur supply chain for sour gas processing and bitumen upgrading operations, Energy Fuels 28, 11, 7252-7267.

14 Casault S., Groen A.J., Linton J.D. (2016) Linking the value assessment of oil and gas firms to ambidexterity theory using a mixture of normal distributions, Oil Gas Sci. Technol. Rev. IFP Energies nouvelles 71, 3, 36.

15 Chufu L., Xiaorong H., Bingzhen C., Qiang X., Chaowei L. (2008) A hybrid programming model for optimal production planning under demand uncertainty in refinery, Chin. J. Chem. Eng. 16, 2, 241-246.

16 Al-Qahtani K., Elkamel A. (2010) Robust planning of multisite refinery networks: Optimization under uncertainty, Comput. Chem. Eng. 346, 985-995.

17 Tong K., Feng Y., Rong G. (2011) Planning under demand and yield uncertainties in an oil supply chain, Ind. Eng. Chem. Res. 51, 2, 814-834.

18 Leiras A., Elkamel A., Hamacher S. (2010) Strategic planning of integrated multi-refinery networks: a robust optimization approach based on the degree of conservatism, Ind. Eng. Chem. Res. 49, 20, 9970-9977.

19 Oliveira F., Hamacher S. (2012) Optimization of the petroleum product supply chain under uncertainty: A case study in northern Brazil, Ind. Eng. Chem. Res. 51, 11, 4279-4287.

20 Ribas G.P., Hamacher S., Street A. (2010) Optimization under uncertainty of the integrated oil supply chain using stochastic and robust programming, Int. Trans. Oper. Res. 17, 6, 777-796.

21 Al-Othman W.B., Lababidi H.M., Alatiqi I.M., Al-Shayji K. (2008) Supply chain optimization of petroleum organization under uncertainty in market demands and prices, Eur. J. Oper. Res. 189, 3, 822-840.

22 Andersson H., Christiansen M., Fagerholt K. (2010) Transportation planning and inventory management in the LNG supply chain. Energy, natural resources and environmental economics, Springer, Berlin Heidelberg, pp. 427-439.

23 Grønhaug R., Christiansen M. (2009) Supply chain optimization for the liquefied natural gas business, Innovations in distribution logistics, Springer, Berlin Heidelberg, pp. 195-218.

24 Özelkan E.C., D'Ambrosio A., Teng S.G. (2008) Optimizing liquefied natural gas terminal design for effective supply-chain operations, Int. J. Prod. Econ. 111, 2, 529-542.

25 Pishvaee M.S., Razmi J., Torabi S.A. (2012) Robust possibilistic programming for socially responsible supply chain network design: A new approach, Fuzzy Sets Syst. 206, 1-20.

$26 \mathrm{Yu}$ C.-S., Li H.-L. (2000) A robust optimization model for stochastic logistic problems, Int. J. Prod. Econ. 64, 1, 385-397.

27 Mulvey J.M., Vanderbei R.J., Zenios S.A. (1995) Robust optimization of large-scale systems, Oper. Res. 43, 2, 264-281.

28 Bertsimas D., Sim M. (2004) The price of robustness, Oper. Res. 52, 1, 35-53.

29 Ben-Tal A., Nemirovski A. (1998) Robust convex optimization, Math. Oper. Res. 23, 4, 769-805.

30 Zekri A., Jerbi K. K. (2002) Economic evaluation of enhanced oil recovery, Oil Gas Sci. Technol. - Rev. IFP Energies nouvelles 57, 3, 259-267. 


\section{Appendix}

\section{Nomenclature}

Sets

$\boldsymbol{s} \quad$ set of production and processing plants of sector $s$

$M^{s} \quad$ set of demand sources for sector $s$

$P^{s} \quad$ set of items in for sector $\mathrm{s}$

$T$ set of periods in the planning horizon

$w$ uncertain scenario

\section{Parameters}

$C B_{i}^{S}$

$C C_{i}^{R, K}$

$C F_{i, j}^{s}$

$C L_{i}^{S}$

$C S_{i}^{s, k}$

$C V_{i}^{s, k}$

$P_{i, t}^{s}$

$S_{i, t}^{s, k}$

$S_{\max }^{s}$

$V_{i, \max }^{D, k}$

$V_{i, \max }^{p, k}$

$V_{\max , t}^{C}, V_{\min , t}^{C}$

$V C_{\max , t}^{R, k}, V C_{\min , t}^{R, k}$

$\delta_{j}^{s}$

$\gamma_{i, j}^{D, k}$ unit backlog penalty of product $i$ for sector $s$

unit cost of processing crude of type $i$ in refinery $k$

unit freight cost of product $i$ to demand source $j$ for sector $s$

unit lost demand penalty of product $i$ for sector $s$

unit storage cost of product $i$ at plant $k$ for sector $s$

unit production cost of product $i$ from plant $k$ for sector $s$

unit Free-on-Board (FOB) price of product $i$ at the end of period $t$ for sector $s$ quantity kept in stock of product $i$ at the end of period $t$ at plant $k$ for sector $s$ maximum storage capacity for product $i$ from all production sites/plants of sectors

maximum production capacity of downstream chemical product $i$ by plant $k$ per planning period

maximum production capacity of petrochemical $i$ by plant $k$ per planning period maximum and minimum limits of crude oil production of all types for planning period $t$

maximum and minimum throughput of crude mix to refinery $k$ for planning period $t$

degree of uncertainty

lost demand fraction of non-served cumulated demand by sector $s$ for market $j$ (assumed equal to $5 \%$ in all business sectors)

yield of product $i$ that is produced by plant $k$ in sector $s 2\{R, P, D\}$ from feedstock $j$
${ }_{i}^{P, k} \in\{0,1\}, 1$ if product $i$ produced by petrochemical plant $k$ is used as a feedstock to downstream chemical plants, 0 otherwise

${ }_{i}^{R, k} \in\{0,1\}, 1$ if product $i$ produced by refinery $k$ is used as a feedstock to petrochemical plants, 0 otherwise

$n \in(0,1)$, The coefficient of average

$1-n \in(0,1)$, The coefficient of variance

$p_{w} \quad$ The probability of each scenario

\section{Variables}

$B_{i, j, t}^{s} \quad$ backlog quantities of product $i$ to demand source $j$ at the end of period $t$ for sector $s$

$D_{i, j, t}^{s} \quad$ demanded quantities of product (crude oil type) $i$ from sector $s$ by market $j$ for period $t$

$F_{i, j, t}^{s, k} \quad$ shipped quantities of product $i$ to demand source $j$ at the end of period $t$ from plant $k$ of sector $s$

$L_{i, j, t}^{S} \quad$ lost demand quantities of product $i$ to demand source $j$ at the end of period $t$ for sector $s$

$V C_{i, t}^{R, k} \quad$ quantity of crude of type $i$ processed by refinery $k$ during the period $t$

$V D_{i, t}^{P, k} \quad$ quantity of petrochemical product $i$ produced by petrochemical plant $k$ and used as a feedstock to the downstream chemical plants at planning period, $t$

$V P_{i, t}^{R, k} \quad$ quantity of refinery product $i$ produced by refinery $k$ and used as a feedstock to the petrochemical plants at planning period, $t$

$Z \quad$ value of the objective function

$z^{s} \quad$ profitability related to sector $s$ in the objective function

$q_{w}^{+}, q_{w}^{-} \quad$ The variance of objective function for each $w$

$q_{c, w}^{+}, q_{c, w}^{-}$The objective function variance for crude oil sector for each $w$

$q_{s, w}^{+}, q_{s, w}^{-}$The answers variance for petrochemical and downstream sectors for each $w$

$q_{r, w}^{+}, q_{r, w}^{-}$The answers variance for refinery sector for each $w$

$\varphi_{w}^{+}, \varphi_{w}^{-} \quad$ The constraint violation for $j$ constraint for each $w$

\section{Superscripts and subscripts}

$C$ crude oil production sector

$D$ downstream chemicals industry sector

$P$ petrochemical industry sector

$R$ refining sector 